The tin is obtained by the difference in weight, calculating the antimony to $\mathrm{Sb}_{2} \mathrm{O}_{4}$. From every 20 per cent. tin so obtained, subtract one-tenth per cent., as explained previously.

In conclusion, we may add that any scheme which ignores the antimony passing into the nitric acid solution when the alloy is oxidized, is not worth considering. Working on one gram it amounts to from three to four per cent. of antimony, calculated on the alloy. Some results point to the feasibility of making correction for this solubility instead of holding back the main precipitate for it.

THE DUQUESNE CHEMTCAL LABORATORY, Pitssburg, Pa.

[CONTRIBUTION FROM THE JOHN HARRISON LABORATORY OF CHEMISTRY, No. 24.]

\title{
THE CONSTITUTION OF ARSENOPYRITE.
}

BY F. W. STARKE, H. I, SHOCK, AND EDGAR F, SMITH.

Received October 30,1897 .

THIS mineral is generally described as a sulpharsenide of iron. It has never been determined in what state of oxidation the iron exists, although it is customary to express the composition of the mineral by the formula FeSAs, in which some chemists have thought that the arsenic functions as a dyad element, that arsenopyrite consequently is nothing more than ordinary pyrite, in which an atom of arsenic has replaced an atom of sulphur, or that it is an iron arsenide in which sulphur, acting with a valence of three, has replaced arsenic. There is no experimental evidence favoring either assumption.

Pyrite and marcasite have been studied with the view of ascertaining the condition of the iron in them.' It was discovered that the first contained about one-fifth of its total iron content in the ferrous condition, whereas all the iron in marcasite existed in the ferrous state. Subsequent experiments have amply confirmed this observation. Efforts were also made to determine the nature of the iron in arsenopyrite. ${ }^{2}$ These resulted negatively.

The present communication presents experimental results

1 A. P. Brown: Am. Phil. Soc. Proc., 1894.

2 T. M. Lightfoot: This Journal, Sept., I 894. 
obtained during the last few years. These in no wise conclusively prove the constitution of arsenopyrite, but they do furnish data which in the future, perhaps, may prove helpful in the solution of the chief problem.

One of the first steps undertaken was the exposure of arsenopyrite to a current of hot hydrogen. The mineral was placed in a porcelain boat, contained in a combustion tube, and gently heated while the gas passed over it, care being taken that the temperature did not become so great as to break down the hydrogen sulphide produced in the experiment. Some arsenic was also volatilized. Repetitions of the experiment were made and the escaping gases were collected in receivers containing hydrochloric acid and bromine. The sulphur expelled in this manner equaled 19.92 per cent. Perfectly pure arsenopyrite, FeSAs, contains 19.63 per cent. of sulphur. Here then we have evidence of the quantitative expulsion of the sulphur content. The contents of the boat showed arsenic and iron. The traces of the former observed over the boat and in the tube indicate that the arsenic was not so readily separated from its union with the iron, and therefore we may justly infer that the sulphur was less intimately combined. Returning to pyrite and marcasite, we found that they also, when heated in an atmosphere of hydrogen, lost one atom, or one-half, of their sulphur. This would be fair evidence for the assertion that a sulphur atom in each of these bodies was less intimately combined, and this would argue for a similarity of these minerais in this respect.

Arsenopyrite was next intimately mixed with dry ammonium chloride and heated in an atmosphere of pure nitrogen. On dissolving the boat contents in water and applying suitable tests much ferrous iron was indicated, and at the same time evidences of ferric salts were distinctly observed. As nothing definite in regard to quantity could be ascertained in this way, portions of finely divided mineral were heated with copper sulphate, of varying strength, in sealed tubes. A number of complete decompositions were obtained, but on attempting to titrate the ferrous iron with potassium permanganate, as had been done with marcasite, more iron was found than the mineral actually contained. This meant that some other reducing agent than ferrous salts was present. And in this instance it was no doubt 
arsenious oxide. This procedure could not, therefore, be regarded as sufficiently reliable to afford an idea of the correct amount of iron in the ferrous state. It served merely to further substantiate the hint gained by heating the mineral with an. monium chloride.

Experiments made upon the direct action of gaseous haloids on sulphide of arsenic proved that the latter was wholly volatilized. It was, therefore, natural to suppose that these reagents might possibly eliminate arsenic from its naturally occurring compounds. To this end hydrogen bromide, which had been conducted over red phosphorus and phosphoric anhydride, was passed in the cold over a boat containing finely divided arsenopyrite. At first there was no apparent action. On applying a very gentle heat a yellow-colored sublimate appeared in the cooler portions of the tube. The boat contents became crystalline and yellowish.green in color. Both ferrous and ferric iron were found, the latter, however, in not very great amount. Several quantitative trials were made:

Experiment $1 .-0.2395$ gram of material heated in hydrogen bromide gave a product soluble in water. When the aqueous solution was titrated with potassium bichromate, it showed the presence of $28.7 \mathrm{I}$ per cent. of iron in the ferrous state.

Experiment 2.- 0.1507 gram of the material treated as in $I$, gave 27.93 per cent. of ferrous iron.

Experiment 3.- O.I 720 gram of the arsenopyrite, treated as in $I$ and 2 , showed 26 .I I per cent. of iron in the lower state of oxidation.

The variation in the ferrous content in these three trials can easily be explained. To effect the complete decomposition of the mineral, it was necessary to raise the temperature, and this was attended by a slight dissociation of the hydrogen bromide and a consequent partial oxidation of the iron. The experiments, however, possessed value, as they helped to confirm previous efforts in that they showed the presence of a predominating quantity of iron in the lower state of oxidation.

We next resolved to substitute dry hydrogen chloride gas for the hydrogen bromide. When this was done arsenic chloride and a little ferric chloride were carried over into the receiver. The boat contents were white in color and dissolved completely 
in water. Some quantitative determinations were made as described under the hydrogen bromide decompositions.

Experiment $J .-0.0682$ gram of arsenopyrite, when heated in hydrochloric acid gas, left a residue in the boat, which was soluble in water, and when the aqueous solution was titrated 30.86 per cent. of ferrous iron was found.

Experiment 2.- -1332 gram of the material under similar treatment showed 30.55 per cent. of ferrous iron.

Experiment 3.- 0.1675 gram of substance subjected to the same treatment as in $I$ and 2 , gave 30.16 per cent. of iron in the lower state of oxidation.

These results are concordant and may be accepted as showing the probable amount of ferrous iron in arsenopyrite, the total iron content of which is 34.35 per cent. This would leave about four per cent. of the iron existing in the ferric condition.

The arsenic collected in the receiver gave an immediate precipitate on the addition of hydrogen sulphide, thus arguing for the trivalent condition of that metal. Further, no precipitation occurred with a "magnesia mixture," evidence again of the absence of quinquivalent arsenic, and lastly, in all the complete decompositions of arsenopyrite brought about by copper sulphate, the consumption of potassium permanganate was far in excess of what was required by the iron, even if all of the latter had existed in the ferrous state. It is, therefore, reasonable to assume that arsenic in the trivalent condition was the cause of the excessive reduction, as no other reducing agent was present.

The facts fairly well established by the preceding experiments are: ( $\mathrm{r}$ ), that about seven-eighths of the total iron content represent ferrous iron, the remaining eighth being ferric iron; (2), that the total arsenic is in the trivalent condition. The readiness, furthermore, with which all of the sulphur is removed by hydrogen, would argue for a less intimate union of this element, and indeed that it is scarcely likely that it is in direct combination with the iron.

Any attempt to graphically represent these conditions must be regarded as entirely tentative and indeed speculative in the highest degree. The facts can be empirically represented in the formula ${ }_{14} \mathrm{Fe}^{\prime \prime} \mathrm{As}^{\prime \prime \prime} \mathrm{S} .2 \mathrm{Fe}^{\prime \prime \prime} \mathrm{As} s^{\prime \prime} \mathrm{S}$, beyond which we are not justified in going. However, were it not for the slight ferric 
content, the constitution of arsenopyrite might be graphically written

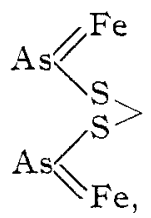

and all the conditions of experiment fully satisfied. We cannot expect much from such speculative formulas, until we have better and satisfactory evidence in regard to the size of the molecuie. Until methods have been devised for the determination of the molecular magnitude of minerals, it will be wiser to merely state the facts, leaving it to future workers to collate them. It may not perhaps be out of place to observe that we endeavored to discover some suitable means of determining mineral molecular magnitudes, but we are still destitute of anything approaching even an approximate method. We sought to learn what influence a weighed quantity of arsenopyrite would exert upon the solidification point of low fusing alloys, e. $g$., Rose's metal, Wood's metal, without arriving at anything definite. And in the case of certain related minerals (marcasite and pyrite) specific heat and electric conductivity experiments were carried out in the hope of detecting differences connected with varying constitution, but such proved not to be the case.

UNIVERSTT OF PENNSYLVANIA.

\section{ESTIMATION OF MINERAL MATTER IN RUBBER GOODS.}

BY I. DE KONINGH.

Received October $29,289 \%$.

I $T$ is a well known fact that the amount of mineral matter in rubber goods cannot be determined by means of a simple ignition, as the ash does not represent the original mineral matter. For instance, white lead becomes lead oxide, chalk is largely reduced to calcium oxide, some oxides volatilize, etc. By using the following process the writer believes he has effected a decided improvement. Five grams of the very finely divided sample are treated in a covered beaker with fifty $c c$. of fuming hydrochloric acid, and after soaking for an hour, the 